\title{
A concept to Reduce Idle Time on Stevedoring Activities in a Container Terminal
}

\author{
Nurul Khafid ${ }^{1}$, Bambang Syairudin ${ }^{1}$
}

\begin{abstract}
The flow of goods is still dominated by sea transport compared with other modes of transport so that the container terminal is very important role in the economic system of a country. The main indicator of performance of a container terminal is the total container throughput in TEUs per year. Recording is done in the process of stevedoring activities. It was found that the idle container cranes (CC) increases higher than the increase in throughput that is $77 \%$ compared with $22 \%$. This should not apply instead. Waiting for a load and Combined Terminal Tractor (CTT) / truck are the largest contributor to the idle CC. No one can be sure that the cargo does not exist because there is no CTT which brings, or the container is not ready. The results showed that by changing the arrangement of CC and CTT obtained the increase in number of containers underserved. Another result is a decrease in the average number of ships that was rejected due to full berth and unloading equipment utilization.
\end{abstract}

Keywords-Stevedoring, Idle Time, Simulation Modeling, CTT.

\section{INTRODUCTION}

Sea freight traffic is increasing in line with the needs of imports and exports to support economic growth. Port as doorway goods trade plays a very important function. The whole process is in port, such as loading and unloading, stacking, and delivery/receiving should be ensured to run smoothly.

PT. Terminal Teluk Lamong (TTL) is a subsidiary of Pelindo 3 which has concessions in the zone of the port of Tanjung Perak. The company is administratively located in the village of Tambak Osowilangun, district Benowo Surabaya. To access the entire facility can only be through the street Tambak Osowilangun Surabaya. Geographic location of PT. TTL is at east longitude -7.2003715 and $112.6797814,6032$ southern latitudes of the earth.

Since the operation of 2015, the number of ship arrivals increasing every year. This situation is offset by the increase in the number of loading and unloading equipment. On the other issues related to work safety and quality of care is still widespread. Improving the system and procedures of quality and safety as the demands of quality standards and legislation on safety, security, health and the environment continue to be made. To the terminal manager is required to ensure that the smooth operation of container handling services become essential to be met.

\footnotetext{
${ }^{1}$ Nurul Khafid and Bambang Syairudin are with Management Technology, Institut Teknologi Sepuluh Nopember, Surabaya, 60111 Indonesia. E-mail: nkhafid@gmail.com; bambangsyairudin@gmail.com.
}

\section{STUDY LITERATURE}

\section{A. Layout and Container Terminal Facilities.}

Container is relatively uniform box whose contents do not need to be dismantled at any point of transfer. They have been designed for the handling of goods easier and faster. In addition to excess discharge and loading processes, standardization of the metal box provides many advantages for the customer, because there is protection against weather and theft, and scheduling and better control and simplified, resulting in a profitable cargo flows. Regarding operations, we need to distinguish whether we are referring only to the container (which in this case is called a box) or we determine the type of container that is being considered. The most common differences refer to the standard container is referred to as the length of twenty feet (20'), which describes the short-length container. Other containers are measured using this container, namely twenty-foot equivalent unit (TEU) (e.g., container 40 'and 45 ' represents 2 TEU). Additional container properties can be specified whenever appropriate (e.g., heavy or heavy container classes, need for special handling of oversized reefer container or container)[1].

TTL is a terminal located on the side of the shallow sea it pertained artificial pier. Layout $\pi$-shaped terminal that docks and yard associated with several trestle (bridge) for a separate location and ships docked at a position parallel to the dock[2]. There are similarities between the definitions and conditions in the terminal layout but there is only a trestle number 1 . Further stated that the implications of this type of layout that is should use the automated guided vehicle (truck) more to achieve the most optimal throughput[2].

TTL in the operation of container terminals have facilities and loading and unloading equipment. Its main facility is the berths, docks, transport, yard and gate. Seaside term facilities intended for the first two, while the last 2 commonly referred to as the landside [4]. As for transport is as the intersection between the landside and seaside in the form of trestle along 1.5 kilometres. Major equipment owned by the form of 10 units of container crane (CC), which is in the wharf. There are 10 units of automated stacking cranes (ASC) in the yard. Used to transport 50 units combined model of the truck tractor terminal (CTT) and 5 units of the straddle carrier (SC).

\section{B. Operation in Container Terminal.}

One of the services the terminal is stevedoring work of raising and lowering the load or from/to the vessel. 
Container stevedoring operations started from ships docked ship moored at the berth. Then one by one container is moved from the ship to a truck to be taken to the yard. Straddle carrier takes container off the truck and take it down at the front end of the block. ASC automatically pick it up and bring into the block container yard (CY) to be stacked. Architecture block as it is generally found in many European ports. While in Asia, trucks can enter the block and parked under the crane to take the load[3]. The process of unloading container services then it goes upside process that starts from the block CY and ended up on the ship.

CY is divided into 5 blocks. Each block is placed 2 ASC unit identical (twin ASC), which works in semi-automatic. Crane freely handle each side of the block to the overlapping area along the block itself. The point is that if one crane breakdown and parked in the repair area is at the end block of the partner can replace in full[3].

Selection method of stacking/retrieval container automatically,[4] is based on several reasons, including the lack of a reliable operators, the high wages of the operator or the needs of ongoing operations. In this case, speed is the main reason. Thus, the process of stevedoring expected to run smoothly without any obstacle from the landside. Despite these factors or to transport container from the ship tried to overcome by using a truck that can be operated manually or automatically. Stated that the customer no matter what tool is used to handle containers that are important cost less and are shorter. It is measured by the length of time in dock for mooring the vessel stevedoring[4].

\section{Idle Time}

The formulation of the berthing time (BT) is the total effective time (ET) coupled with idle time (IT), and time does not operate (NOT). IT components such as the waiting cargo (container), waiting for the truck, equipment breakdowns, and bad weather. In other hand NOT such as an over shift, lunch time and praying time[5]. Additionally, stated to reduce BT can be done by reducing the length of time taking container from the stack and container trip to the berth. From this point, it can be concluded that the waiting cargo can be caused by two things[6]. To reduce the load time of a container yard, in addition to a balanced arrangement in the yard will reduce the risk of a build-up of container in the flow transports or bottleneck in container terminal operations. The solution to adjust the placement of the container are: first, classifying container load time based on each - each block and the second, container placement in blocks based on the ship to be loaded[7].

As stated above that the yard and wharf connected by a trestle then 1 cycle time will be greatly influenced by the truck scheduling and allocation placement. This was disclosed[8] as a highly interdependent problem in the operation of container terminals. It suggested that the balance between truck transport from/to the wharf to the time of placement of containers to obtain the shortest total operating cycle. The problem of idle time has also been discussed [6] using Genetic Algorithm by incorporating factors terminal layout, stacking rules, and the amount of equipment used cumulation. Stacked container to be loaded close to the side of the dock will reduce the time compared to accumulate randomly within a block.

The application of semi-automatic terminal is a response to the increasing size of ships getting bigger, of course with loads more too. It is expected to reduce the role of humans could be made more efficient stacking system[9]. It is already implemented and should not be a factor which should be reconsidered. The variables that most influence the capacity of the container terminal associated with loading and unloading equipment and facilities such as the number of terminals, the number of cranes[10], and crane productivity[11]. This study tries to connect between the length of idle time on CC and productivity related to the number and arrangement of CTT. Stevedoring simulation model created to consider without the addition of loading and unloading equipment and operators.

\section{METHOD}

As we know that engineering simulation model is one of the effective methods for the analysis of the terminal system which containing a stochastic process[12]. From here it is a simulation model is created with the purpose of the analysis of several options to reduce the idle time on the equipment which resulted in the increase in terminal performance. Refer to fig. 1 it is described research steps. The study begins by reading the monthly report of operational terminal and direct observation to the field to confirm it. A tallyman records any event occurs under the CC. Every incident happen, tallyman will enter the data that is the starting time of events, the reasons incident and the time incident ended. To facilitate classifying the types of events that have been provided choices of events in the hand-held terminal (HHT) is used. However, there are as many as 49 kinds of selection events. Of course, this number is very large and must be extra careful in his selection. On the other hand, there are reasons written on the side kind of events with free text type, so there are 234 kinds of reasons for Waiting Cargo event. For this reason, the root cause of event or accident is difficult to identify using that data.

There are two main sources of data: server crane monitoring system (CMS) and the terminal operating system (TOS) logbook. Each crane has each CMS which records all the events that occur on the crane which includes: event, alarm, fault, number of containers moved, and hour meters. The data is sourced from a programmable logic controller (PLC) then the data is sent in real time to a CMS server. The format of the data stored in the database. Crane is equipped by CMS is CC and ASC. The second source is derived from the data inputted by the tallymen, CTT operators and SC operators. Operator entering data from vehicle-mounted terminal (VMT) located within the cabin. These data are stored in the server TOS. The author takes data in a form that has been calculated in the period per work shift. 
The conceptual model was made to facilitate transfer real system into the simulation model. The form of a flowchart diagram illustrating the flow of container from the wharf to block CY. The simulation model in the form of a computer program created by the Arena program version 14.0 by Rockwell Automation, Inc.

\section{RESULTS AND DisCUSSION}

\section{A. Modelling of Stevedoring of Container Terminal}

First modelling approach is made. In addition to operating a container terminal, the operator also operates a dry bulk terminal but, in this study, only container terminal was discussed and considered the dry bulk terminal does not give effect to the stevedoring process. The following assumptions were made based on the survey:

- Total CTT did not change throughout process and even if there were a breakdown the direct successor takes over.

- If there are two or more CC are assigned to one vessel it is considered that the CC will begin to work together, and shared workload is divided evenly.

- Speed of SC and Reach Stacker is assumed to be the same all the time with respect to: the number of units corresponding to the block container yard, distance and relatively short operation time.

- Block CY will never be fully considered during the simulation period

- There is no effect on the process of delivery / receiving residing on block CY.

Second, to determinate the system data. The data related to stevedoring taken on January 1, 2017 to December 31, 2017. The data was processed by using the Input Analyzer from Arena then obtained distribution data. For example, in the Fig. 2 the distribution of arrival of the vessel.

\section{B. Verification and Validation Model}

In this case the verification is the process of checking whether the operational logic model in this case a computer program is in conformity with the flow chart. For that use Check Model Arena so he found that there were no warnings or errors in the models. This method is used after the author to make sure every logic module is configured correctly and placed in the location should be. Validation is done to ensure that the model is an accurate representation of the real system by way of the output of the model has significant similarities with the real system. The t-test is used to test the hypothesis of similarity of average values between two real system output data set compared with the model output. The tools used to test $\mathrm{t}$ is t-Test Data Analysis: Two-Sample Assuming Equal Variances provided by Microsoft Excel 2016. This test requires two sets of data and limits the maximum error or alpha $(\alpha)$ is set at 0:05. In table 1 is shown the results of the validation some part of the process of stevedoring. $t$ test is smaller than $\mathrm{t}$ table means the model output equal to the real system.

\section{Running the Simulation and Data Analysis}

CTT CC versus operating duration. CC operation time duration is highest compared to other equipment except CTT. Comparison with CTT, CC operative duration was 5.78: 1, or rounded to 6: 1 . That is for 6 cycles CC operation comparable to the one cycle CTT, for it required 6 units of CTT for each CC in operation. In Fig. 3 simply described the relationship between the equipment. Throughout the years Terminal operate 7 days a week and 24 hours a day. The work is divided into 3 shifts each 8 hours straight without a break certain hours. In 2017 the number of CTT provided as many as 50 units, CC 10 units, 5 units of SC \& 1 unit of RS, and 5 units of ASC. CTT operated in that year 26 units for following the number of carriers available at each work shift.

Based on these conditions then made 4 kinds of simulated scenarios: CTT pattern 5, 6 CTT, 13 and 26 CTT. Pattern 5 CTT is every 1 unit of CC operating the unit will be operated 5 CTT up to at most 26 units. This pattern is like that for 6 CTT. For the pattern 13 CTT means that if there is a 1 to 2 CC operated then there are 13 CTT operates and more of it all the CTT will be operated. The pattern of the 26 CTT CC point is whatever operating then all the CTT will be operated.

In pattern 6 CTT all average the highest utilization except for CTT. As for the average container in handling also suffered the greatest number 38,940 box. It is comparable to the number of vessel mooring rejected due to full, an average of 0.5 vessels. Pattern 13 CTT shows that operate throughout the CTT were prepared at each condition does not provide optimal results with indicated average number of vessels and containers are handled less. Reducing the number of operators on duty CTT will give a great influence on the number of vessels being served, this is indicated on the pattern 5 CTT.

\section{CONLUSION}

The increase in the number of arrivals of ships and containers in the handling requires a pattern of loading and unloading equipment operating settings that provide the best performance of the terminal. Increased utilization will reduce idle time of equipment and result in an increase in the number of ships serviced and terminal throughput. CTT change arrangement patterns of the CC can make a difference without having to increase number of CTT operator or its unit. However, this may not be effective if the number of vessels and containers increased dramatically. 


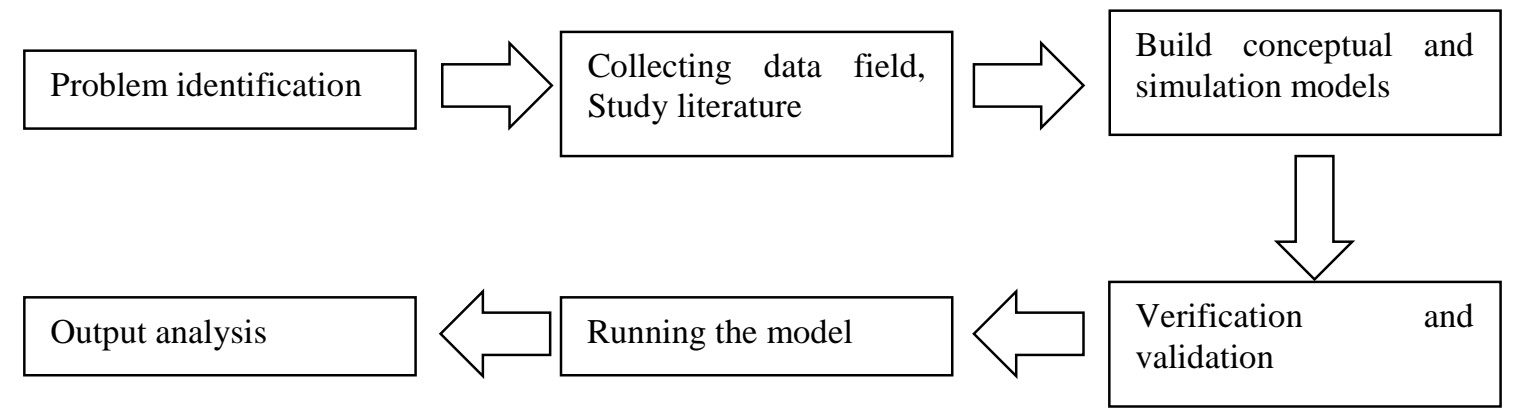

Figure 1. The main steps of the methodology

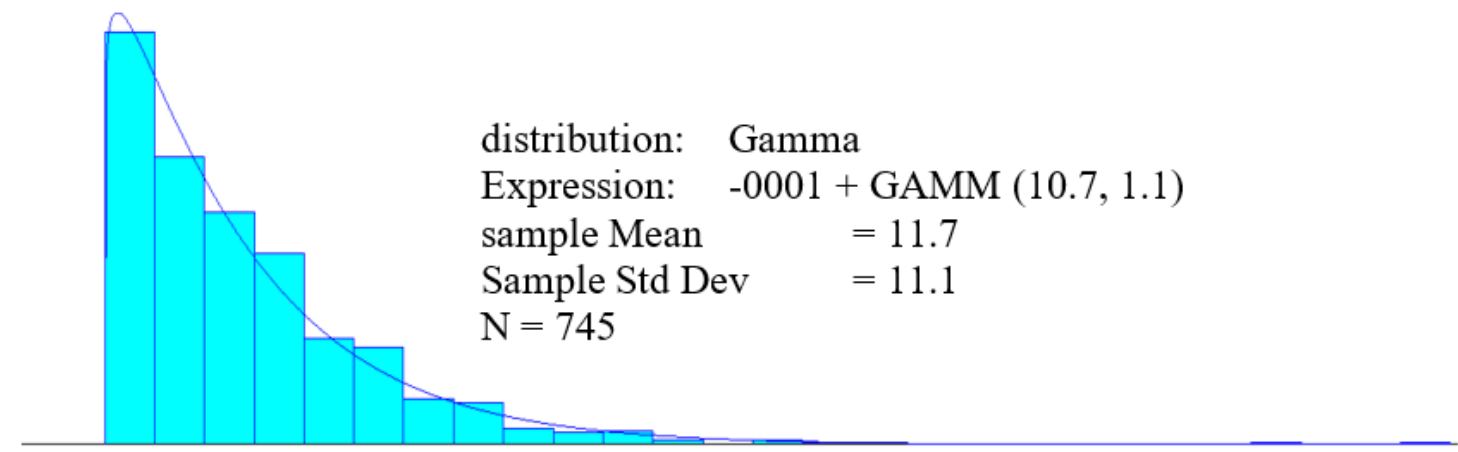

Figure 2. Distribution data between the arrival of the vessel (h).

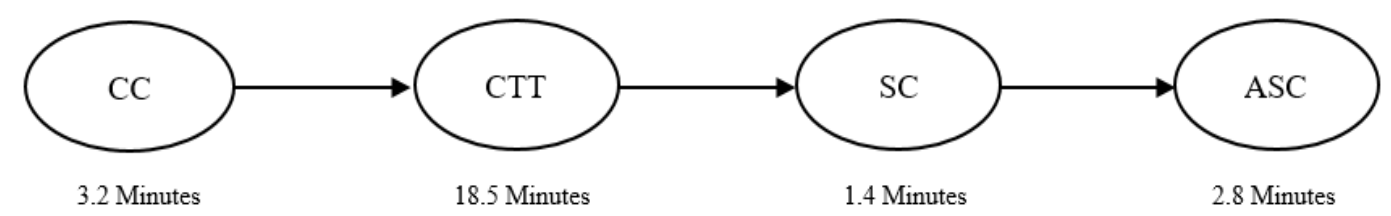

Figure 3. Duration of operation equipment for container handling.

TABLE 1.

VALIDATION SUB-PROCESS STEVEDORING

\begin{tabular}{clcccc}
\hline \hline No. & \multicolumn{1}{c}{ Sub-processes } & Df & t test & t table & Conclusion \\
\hline 1 & The arrival of the ship & 1,488 & 0.41 & 1.96 & valid \\
2 & CC Unloading & 49,858 & 1.17 & 1.96 & valid \\
3 & CTT Moving: Pier to SC & 1,454 & 0.52 & 1.96 & valid \\
4 & SC Moving: CTT to Buffer Area & 1,450 & 1.32 & 1.96 & valid \\
5 & ASC Moving: Buffer Area to Stack & 37,320 & 0.44 & 1.96 & valid \\
6 & Effective Time & 128 & 1.94 & 1.98 & valid \\
\hline \hline
\end{tabular}

TABLE 2.

Utilization AND PERformance Terminal Equipment in AVERAge Value

\begin{tabular}{ccccccc}
\hline Pattern & $\begin{array}{c}\text { CC } \\
\text { Utilization }\end{array}$ & $\begin{array}{c}\text { CTT } \\
\text { Utilization }\end{array}$ & $\begin{array}{c}\text { SC } \\
\text { Utilization }\end{array}$ & $\begin{array}{c}\text { ASC } \\
\text { Utilization }\end{array}$ & $\begin{array}{c}\text { Container } \\
\text { (box) }\end{array}$ & $\begin{array}{c}\text { Rejected } \\
\text { Vessel }\end{array}$ \\
\hline 5 CTT & $23.5 \%$ & $63.0 \%$ & $28.8 \%$ & $35.5 \%$ & 35,441 & 1.33 \\
6 CTT & $25.9 \%$ & $66.1 \%$ & $31.5 \%$ & $38.9 \%$ & 38,940 & 0.50 \\
13 CTT & $25.2 \%$ & $66.2 \%$ & $30.9 \%$ & $38.1 \%$ & 36,910 & 0.92 \\
26 CTT & $25.0 \%$ & $65.7 \%$ & $30.6 \%$ & $37.8 \%$ & 36,850 & 1.17 \\
\hline \hline
\end{tabular}

\section{REFERENCES}

[1] S. Voß, R. Stahlbock, and D. Steenken, "Container terminal operation and operations research - a classification and literature review," OR Spectr., vol. 26, no. 1, pp. 3-49, Jan. 2004.

[2] M. E. Taner, O. Kulak, and M. U. Koyuncuoğlu, "Layout analysis affecting strategic decisions in artificial container terminals," Comput. Ind. Eng., vol. 75, pp. 1-12, Sep. 2014.
[3] H. J. Carlo, I. F. A. Vis, and K. J. Roodbergen, "Storage yard operations in container terminals: Literature overview, trends, and research directions,” Eur. J. Oper. Res., vol. 235, no. 2, pp. 412430, Jun. 2014.

[4] I. F. A. Vis, "A comparative analysis of storage and retrieval equipment at a container terminal," Int. J. Prod. Econ., vol. 103, no. 2, pp. 680-693, Oct. 2006.

[5] R. O. S. Gurning and E. H. Budiyanto, Manajemen bisnis 
pelabuhan. Surabaya: APE Publishing, 2007.

[6] E. Kozan and P. Preston, "Genetic algorithms to schedule container transfers at multimodal terminals,” Int. Trans. Oper. Res., vol. 6, no. 3, pp. 311-329, May 1999.

[7] C. Zhang, J. Liu, Y. Wan, K. G. Murty, and R. J. Linn, "Storage space allocation in container terminals," Transp. Res. Part B Methodol., vol. 37, no. 10, pp. 883-903, Dec. 2003.

[8] J. Cao, Q. Shi, and D.-H. Lee, "A decision support method for truck scheduling and storage allocation problem at container," Tsinghua Sci. Technol., vol. 13, no. S1, pp. 211-216, Oct. 2008.

[9] Y. Huang, C. Liang, and Y. Yang, "The optimum route problem by genetic algorithm for loading/unloading of yard crane," Comput.
Ind. Eng., vol. 56, no. 3, pp. 993-1001, Apr. 2009.

[10] Z. Zenzerovi, M. Jurjevi, R. Pomorski, M. Studies, R. Studentska, and R. Hrvatska, "Queuing theory in function of planning the capacity of the container terminal in Port of Rijeka," Sci. J. Marit. Res., vol. 25, no. 1, pp. 45-69, 2011.

[11] W. Y. Yun and Y. S. Choi, "A simulation model for containerterminal operation analysis using an object-oriented approach," Int. J. Prod. Econ., vol. 59, no. 1-3, pp. 221-230, Mar. 1999.

[12] S. Esmer and O. Tuna, "Liman İşletmeciliğinde Bir Karar Destek Sistemi Olarak Simülasyon Yönteminin Analizi,” Dokuz Eylül Üniversitesi Sos. Bilim. Enstitüsü Derg., vol. 9, no. 4, pp. 120-134, 2007. 